\title{
Vamos fazer o esforço: ciência em latim na Antiguidade ${ }^{1}$
}

\author{
Daryn Lehoux* \\ Tradução de Anna Olga Prudente de Oliveira
}

Enitar ut Latine loquar.

Vou fazer o esforço de dizer isso em latim. - Cícero

O nome científico do grande tubarão branco é Carcharodon carcharias. Isso, comicamente, pode ser traduzido como "tubarão-dos-dentes-de-serra com dentes de serra". Embora possa faltar a majestade do "lagarto-rei rei" do Tyrannosaurus rex, o nome captura sem dúvida um traço proeminente do tubarão branco. Outra diferença entre os dois nomes é que, quando Lineu cunhou C. carcharias, o tubarão já tinha um nome vernacular. Em contraste, o nome do T. rex teve que ser inventado do nada, o que fez o nome científico tornar-se vernacular. Contudo, a ausência de um nome vernacular para o $T$. rex não era uma ausência completa de nomes, pois o que Henry Fairfield Osborn fez foi usar palavras gregas e latinas disponíveis, com as quais produziu uma nova designação. As raízes estavam ali, mas não ainda como o nome de um animal.

O exemplo sinaliza alguns dos problemas enfrentados pelos primeiros tradutores de material científico e filosófico do grego para o latim (Cícero, Lucrécio e outros): nem todas as palavras já existiam na língua meta. Os gregos tinham discutido como o mundo funcionava, de que era feito, $\mathrm{e}$ por que era da maneira que era por vários séculos antes de haver qualquer registro de falantes de latim interessados em participar desses debates. Vo-

\footnotetext{
${ }^{1}$ Este artigo foi originalmente publicado em inglês no periódico Isis: A Journal of the History of Science Today, e pode ser acessado por meio do endereço https://www.journals.uchicago.edu/toc/isis/current *Queen's University.
} 
cabulários técnicos detalhados tinham sido desenvolvidos na Grécia, em todas as áreas, da ética à astronomia. O latim nada tinha dessa capacidade linguística no começo, e decisões tinham que ser tomadas para remediar essa lacuna. E, evidentemente, tradução não é em geral apenas um processo de transformar palavras estrangeiras em nativas. $\mathrm{O}$ tradutor também tem que refletir sobre o que pretende alcançar com uma tradução, como lidar com nuances linguísticas, jogo de palavras e muito mais. Para romanos instruídos, entretanto, essas questões emergiram não apenas no contexto do que vou chamar de tradução textual, que significa para mim o ato familiar de trazer algum texto específico, de modo mais ou menos fiel, de uma língua para outra, mas no contexto do que podemos chamar tradução discurso, o projeto muito maior de pegar toda uma disciplina que até então apenas tinha sido falada e escrita em uma língua, o grego, e tentar inseri-la de modo produtivo em outra, o latim. Para os romanos, a filosofia natural simplesmente nunca havia sido feita em sua língua antes, e não estava claro para eles se podia ser ou mesmo se precisava ser. Afinal, se romanos cultos eram (deveriam ser) capazes de ler e falar grego, então para que a tradução? A quem seria destinada? ${ }^{2}$ A questão da tradução discurso é duplamente interessante nesse caso, porque as primeiras tentativas de fazer filosofia natural em latim talvez sejam a primeira vez na história das ciências em que de fato foi questionado se $o$ ato da tradução em si mesmo era possível ou sequer desejável. Sim, conhecimento divinatório, médico, astronômico e sobre o calendário parece ter circulado livremente entre culturas e línguas antigas antes do período romano. ${ }^{3}$ Mas, no projeto latino, vemos um engajamento ativo e direto com a questão da possibilidade da tradução. A pergunta era simplesmente esta: é possível fazer filosofia - natural ou qualquer outra - em latim?

Como uma indicação de quão cedo e quão profundamente o sentimento pró-grego perpassou a cultura romana, sempre me chamou atenção a referência ao primeiro historiador romano, Quinto Fábio Pictor, ter escrito

\footnotetext{
${ }^{2}$ A questão do bom gosto e da conveniência de legendas na ópera pode servir como um paralelo moderno aqui.

${ }^{3}$ Os detalhes são quase sempre difíceis de estabelecer de modo preciso, mas, entre acádio, egípcio, hitita, hebreu, grego e outras línguas, algo parece ter sido difundido desde os primeiros tempos. Para obter mais detalhes, ver, por exemplo: Neugebauer, 1957; Geller, 2010; Furley; Gysembergh, 2015; e Bachvarova, 2012 .
} 
em grego, e ele fez isso quase um século antes de os romanos de fato incorporarem a Grécia ao império que se expandia em 146 A.E.C. Evidentemente o grego, como língua de educação e cultura, teve desde cedo influência sobre seus vizinhos, e Fábio tomava uma decisão deliberada nesse contexto de não realizar tradução discurso do gênero história. ${ }^{4}$ Não sabemos seus motivos, mas o fato fala por si mesmo: a história era escrita em grego.

Em relação ao material filosófico e científico, o início das interações romanas com esse conteúdo pode ser estabelecido no mínimo em meados do século II A.E.C., quando os atenienses enviaram uma delegação de filósofos a Roma, e quando figuras públicas influentes, como o grande Cipião Emiliano, começaram a patrocinar e a associar-se a filósofos gregos. E é mais ou menos um século depois disso que encontramos nossas primeiras tentativas de tradução de material científico grego: o grande poema atomista de Lucrécio e a considerável obra filosófica de Cícero. Devemos observar, entretanto, que com Lucrécio, assim como com a maior parte da obra filosófica de Cícero, excluindo seus Aratus e Timeu, ${ }^{5}$ o que temos não é uma tradução textual mas, em vez disso, uma tentativa de apresentar os conteúdos de certas doutrinas, comprometendo-se com tais ideias, na nova língua. Hoje Lucrécio é uma de nossas melhores e maiores fontes do epicurismo, mas ele não alega estar representando as verdadeiras palavras do próprio Epicuro. Podemos ainda assim chamar isso de tradução? Talvez não de modo estrito; mas é tradução em um sentido igualmente muito importante, porque o ato de trazer a filosofia grega para o latim, o ato da tradução discurso, era um ato importante para seus praticantes, e eles o viam como uma tarefa significativa: às vezes tentando elevar o nível do discurso ético ou político em Roma; às vezes de olho na autoimagem romana ou apenas na do autor; às vezes, ao

\footnotetext{
${ }^{4}$ Agradeço a um colaborador anônimo por esse ponto.

${ }^{5} \mathrm{O}$ que nos chegou do Timeu de Cícero tem sido visto frequentemente como sendo ao menos uma tentativa de uma tradução autônoma, total ou parcial, do diálogo, que pode ou não ter sido deixada inacabada por ocasião da morte de Cícero; mas David Sedley argumenta, em parte se baseando no próprio material introdutório da obra e no elenco de personagens ali apresentados, que Cícero tinha traduzido deliberadamente apenas uma seção do Timeu, buscando então trazer uma contra-argumentação e ampliar a discussão através de seus outros personagens, notadamente Crátipo, o aristotélico. Acho que essa é uma possibilidade fascinante. Outros, no entanto, têm suas dúvidas. Ver: Sedley, 2013, p. 187-205. Para um posicionamento distinto, ver, por exemplo: Lévy, 2003; e Powell, 1994, capítulo 10.
} 
menos em parte, por virtuosismo. Qualquer que fosse a motivação individual, os próprios romanos consideravam esse trabalho importante e faziam esforços para justificá-lo explicitamente.

Nas primeiras reflexões romanas sobre a conveniência ou a possibilidade de traduzir material filosófico ou científico do grego para o latim, uma comparação é feita em relação ao trabalho (e à adequação) das primeiras latinizações da épica grega. ${ }^{6}$ Embora helenistas posteriores, tais como o autor do século II E.C., Aulo Gélio, possam ter torcido o nariz para os latinos quando comparados aos originais gregos, ${ }^{7}$ pessoas como Cícero achavam que a tradução - tanto discurso quanto textual - cumpria uma finalidade importante, além de possuir qualidades literárias próprias e contribuir para a elevação da cultura e da moral latinas. Escrevendo em uma época em que tinha a vã esperança de salvar a claudicante república da tirania que em breve iria engoli-la, Cícero via o ato de traduzir como, ao menos em parte, uma tentativa de lembrar aos romanos seus mais elevados ideais: “quis enim tam inimicus paene nomini Romano est, qui Ennii Medeam aut Antiopam Pacuvii spernat aut reiciat quod se isdem Euripidi fabulis delectari dicat, Latinas litteras oderit?" ("Quem é tão hostil, mesmo sendo chamado um romano, digamos assim, para condenar e rejeitar a Medeia de Ênio ou o Antíope de Pacúvio, afirmando que sente prazer com as mesmas peças de Eurípedes, mas que detesta a literatura latina?"). Um pouco mais tarde, ele esclarece que seus próprios esforços em traduzir objetivam tornar seus concidadãos "mais instruídos", "doctiores". Na Academica, ele segue no mesmo tom: "tu vero ... Varro, bene etiam meriturus mihi videris de tuis civibus si eos non modo copia rerum auxeris, ut fecisti, sed etiam verborum" ("e tu, ... Varro, me parecerias muito digno de louvor por parte de teus concidadãos se não apenas

\footnotetext{
${ }^{6}$ Sobre isso, ver, por exemplo, Sciarrino, 2006.

7 “Set enim si conferas et componas Graeca ipsa, unde illa venerunt, ... oppido quam iacere atque sordere incipiunt quae Latina sunt" ("Se você compara [as versões latinas] e [as] coloca lado a lado com as gregas que as originaram, as latinas logo começam a parecer tristes e sem valor"): Aulo Gélio, Noctes atticae 2.23.3 (N. T.: Aqui e ao longo deste ensaio, as traduções das citações em latim são minhas, a partir das traduções do latim para o inglês feitas pelo autor Daryn Lehoux). Sobre Aulo Gélio, ver, por exemplo, Howley, 2018.
} 
aumentasses a quantidade de fatos que eles conhecem, como tens feito, mas também de palavras"'). ${ }^{8}$

E aqui chegamos ao tropo mais comum nas discussões latinas dos problemas de tradução: a questão da pobreza do vocabulário latino (e é importante observar que esse problema afeta igualmente ambos os tipos de tradução, discurso e textual). Reiteradamente, os escritores latinos são vistos com a preocupação de disporem das palavras exatas necessárias tanto para fazer ciência quanto filosofia. Assim Lucrécio diz: "nunc et Anaxagorae scrutemur homoeomerian I quam Grai memorant nec nostra dicere lingua I concedit nobis patrii sermonis egestas, I sed tamen ipsam rem facilest exponere verbis" ("agora vamos ver a homoeomeria de Anaxágoras, como os gregos chamam, que não é possível nomear em nossa língua, a falta de nossos próprios termos nativos impedindo-nos, mesmo que a coisa em si seja fácil de explicar em palavras"). Algumas décadas depois, o poeta astrológico Manílio retornaria ao tema: "et, siqua externa referentur nomina lingua, I hoc operis, non vatis erit: non omnia flecti I possunt, et propria melius sub voce notantur" ("e se essas coisas são ditas em palavras de uma língua estrangeira, isso se deve ao assunto, não ao mensageiro: nem tudo pode ser traduzido; há o que é melhor denotado em sua própria voz"). ${ }^{9}$

Cícero, por outro lado, faz um esforço deliberado de trabalhar com palavras de radical latino, mesmo que isso signifique cunhar formas novas. Na verdade, como é muitas vezes observado, os acréscimos que Cícero fez ao vocabulário latino são significativos (imagine fazer filosofia sem palavras para "evidência”, "essência", "humanidade", "moral”, ou "qualidades", entre muitas outras). E retrabalhar a língua deveria ser perfeitamente aceitável, como Cícero aponta: mesmo os gregos, outrora, não tinham palavras para muitas ideias importantes. Eles também precisaram cunhar palavras para discutir novos temas, então por que aos falantes de latim não seria permitido fazer o mesmo? ${ }^{10} \mathrm{E}$, de fato, é importante para a autoimagem de Cícero,

\footnotetext{
${ }^{8}$ Cícero, De finibus 1.4; e Cícero, Academica 1.26.

${ }^{9}$ Lucrécio, De rerum natura 1.830-834; e Manílio, Astronomica 3.40-43.

${ }^{10}$ Cícero, Acad. 1.25-26. Entendo que Cícero pensa que se deve ter uma liberdade considerável, em grego ou latim, para formular palavras ou retrabalhar as já existentes. Em contraste, no Crátilo de Platão (como um colaborador anônimo me lembrou), o personagem Crátilo argumenta que as palavras são inerentes a seus referentes, no sentido de que a palavra captura naturalmente a verdadeira essência da coisa que
} 
como romano, que a capacidade do latim de acomodar-se a esses novos assuntos mostre, não sua pobreza, mas sim uma de suas forças: "sentio et saepe disserui Latinam linguam non modo non inopem, ut vulgo purtarent, sed locupletiorem etiam esse quam Graecam" ("Acredito - e tenho sempre dito isso - que a língua latina não tem problemas com falta de recursos, como normalmente se supõe, mas sim é ainda mais rica do que o grego"). Esse sentimento se coaduna com uma ideia que Cícero defende em outros lugares e que depois autores latinos irão endossar, a de que os romanos não estão apenas traduzindo conteúdo grego, mas melhorando esse material: "non quia philosophia Graecis et litteris et doctoribus percipi non posset, sed meum semper iudicium fuit omnia nostros aut invenisse per se sapientius quam Graecos aut accepta ab illis fecisse meliora" ("não é que não se possa aprender filosofia com os escritos e professores gregos, mas sempre achei que nós, romanos, descobrimos tudo por nós mesmos de modo mais sábio do que fizeram os gregos, ou então melhoramos as coisas que recebemos dos gregos" ${ }^{\prime \prime}{ }^{11}$

Dito isso, o tropo de que algumas coisas eram mais difíceis de dizer em latim do que em grego permaneceu um lugar comum na literatura durante todo o período romano, comparável em alguns aspectos ao bordão dos poetas sobre a dificuldade de versificar material científico. De Lucrécio, novamente: "nec me animi fallit Graiorum obscura reperta I difficile illustrare Latinis versibus esse, I multa novis verbis praesertim cum sit agendum | propter egestatem linguae et rerum novitatem" ("não escapa da minha observação que as obscuras descobertas dos gregos são difíceis de esclarecer em versos latinos, especialmente porque isso muitas vezes deve ser feito com palavras novas devido à pobreza de nossa língua e à novidade do assunto"). Compare isso a Manílio: "certa cum lege canentem I mundus et immenso vatem circumstrepit orbe I vixque soluta suis immittit verba figuris" ("o

\footnotetext{
indica e jamais poderia ser de fato substituída por alguma outra palavra. Nomes verdadeiros jamais poderiam ser adotados por convenção ou simples decreto, como tanto Cícero e Sócrates no Crátilo parecem fazer de modo tão tranquilo. Observe-se que, embora seja significativamente distinta, a proposição de Crátilo é semelhante à alegação em certas tradições de que alguma língua específica captura a verdadeira natureza das coisas. Como o Crátilo deixa claro, os egípicios podem fazer machados de modo diferente do que eu faço, mas seus machados ainda se conformam à natureza da madeira e à natureza do corte.

${ }^{11}$ Cícero, De fin. 1.10; e Cícero, Tusculanae disputationes 1.1. Ver também, por exemplo, Cícero, De re publica 3.5 f.; e Beagon, 2005, p. 50 f.
} 
mundo em sua imensa esfera ecoa em torno do poeta, a cantá-lo em metro fixo ainda que sua natureza dificilmente possa ser apreendida mesmo em prosa"). E pouco depois ele comenta que é o primeiro de todos a tentar tratar de astrologia em versos: "hoc mihi surgit opus non ullis antesacratum I carminibus" ("essa obra ergue-se diante de mim, nunca antes consagrada por outros em verso"). Tanto em Manílio quanto em Lucrécio, o efeito dessa autoconsciência poética é gerar no leitor uma sensação, como Katherina Volk chamou, de "simultaneidade poética", uma sensação de que o poema está surgindo diante dos próprios olhos do leitor. Algo semelhante ocorre, gostaria de dizer, nas reflexões autoconscientes ao longo de toda a literatura científica romana sobre a questão da tradução para o latim. Mesmo quando o projeto já não é mais novo, reflexões sobre a latinização da filosofia natural emprestam vivacidade ao projeto de um autor e reivindicam uma novidade importante. Mesmo posteriormente, no século IV E.C., encontramos o astrólogo Fírmico Materno relatando que outros antes dele deixaram de traduzir a doutrina astrológica "por causa das limitações da língua latina (propter Latini sermonis angustias)." Mas ele, por sua diligência e trabalho árduo, encontrou uma forma de tirar vantagem das "manifestas liberdades da língua dos romanos (ostensa Romani sermonis licentia) para trazer a "ciência divina" a todos os romanos. ${ }^{12}$

E isso, talvez, seja a questão central. Aulo Gélio pode ter achado que as traduções latinas eram insignificantes comparando-as ao grego, mas os tradutores da ciência grega não concordavam, vendo o engajamento com a filosofia natural não somente como possível em sua própria língua, mas fortemente desejável. A fluência em grego talvez tenha sido uma parte importante para a autoimagem dos romanos instruídos, mas, como Cícero observou, isso foi às vezes mais glorificado na ruptura. ${ }^{13} \mathrm{E}$ de todo modo, em uma época de grande agitação política, justamente quando o antigo sistema republicano de governo estava se desintegrando, os projetos empreendidos por Cícero e Lucrécio para trazer o melhor da filosofia grega para o latim tinham tudo a ver com o estabelecimento de um novo tipo de autoimagem romana,

\footnotetext{
${ }^{12}$ Lucrécio, DRN 1.136-139; Manílio, Astron. 1.22-24, 113-114; e Fírmico Materno, Mathesis 4.pr.5. Ver também Volk, 1997.

${ }^{13}$ Cícero, De fin. 1.10 .
} 
que valorizava ativamente a virtude política em detrimento de ganhos financeiros. $\mathrm{O}$ fato de que ambas as suas teorias éticas eram baseadas em concepções de natureza como lei significava que a filosofia natural era uma parte importante desses projetos. Que isso podia ser feito em latim era o que eles queriam provar. De que isso devia ser feito eles não tinham dúvida.

\section{Referências}

BACHVAROVA, M. The transmission of liver divination from east to west. Studi Micenei ed Egeo-Anatolici, 54, p. 143-164, 2012.

BEAGON, M. The elder Pliny on the human animal: natural history book VII. Oxford: Oxford Univ. Press, 2005.

FURLEY, W.; GYSEMBERGH, V. Reading the liver: papyrological texts on ancient greek extispicy. Tubingen: Mohr Siebeck, 2015.

GELLER, M. Ancient babylonian medicine: theory and practice. Chichester: Blackwell, 2010.

HOWLEY, J. Aulus Gellius and roman reading culture: text, presence, and imperial knowledge in the "Noctes Atticae". Cambridge: Cambridge Univ. Press, 2018.

LÉVY, C. Cicero and the Timaeus. In: REYDAMS-SCHILS, G. (Ed.). Plato's “Timaeus" as cultural Icon. Notre Dame, Ind.: Univ. Notre Dame Press, 2003, p. 95-110.

NEUGEBAUER, O. The exact sciences in antiquity. Providence, R.I.: Brown Univ. Press, 1957.

POWELL, J. G. F. Cicero the Philosopher: Twelve Papers. Oxford: Oxford Univ. Press, 1994.

SCIARRINO, E. The introduction of epic in Rome: cultural thefts and social contests. Arethusa, 39, p. 449-469, 2006.

SEDLEY, D. Cicero and the Timaeus. In: SCHOFIELD, M (Ed.). Aristotle, Plato, and pythagoreanism in the first century B.C.: new directions for philosophy. Cambridge: Cambridge Univ. Press, 2013.

VOLK, K. Cum carmine crescit et annus: Ovid's fasti and the poetics of simultaneity. Transactions of the American Philological Association, 127, p. 287-313, 1997. 


\title{
Resumo
}

A escrita científica chegou inicialmente aos falantes de latim da Antiguidade como uma disciplina estrangeira. Fontes da língua grega, sob a forma de textos escritos e também de falantes, trouxeram uma vasta gama de material filosófico, técnico e científico a seus vizinhos latinos desde pelo menos o século II A.E.C. O desafio para os romanos, entretanto, não era apenas o de traduzir textos individuais - de verter o Timeu de Platão para o latim, por exemplo. Em vez disso, os romanos indagavam-se e refletiam abertamente sobre a questão mais ampla a qual este ensaio chama de tradução discurso: Era possível - de algum modo - fazer mesmo filosofia em latim?

Palavras-chave: Tradução científica; Tradução discurso; Tradução textual; Filosofia latina.

\begin{abstract}
Scientific writing initially came to ancient Latin speakers as a foreign discipline. Greek-language sources, in the form both of written texts and of living speakers, brought a wide range of philosophical, technical, and scientific material to their Latin neighbors from at least the second century B.C.E. The challenge for the Romans, though, was not just one of translating individual texts - of turning Plato's Timaeus into Latin, for example. Instead, Romans worried and openly reflected on the broader question of what this essay calls discourse translation: Was it possible-at all-even to do philosophy in Latin?
\end{abstract}

Keywords: Scientific translation; Discourse translation; Textual translation; Latin philosophy. 